\title{
OnabotulinumtoxinA for neurogenic detrusor overactivity and dose differences: a systematic review
}

\author{
Rui Zhang ${ }^{1,2}$, Yongteng $\mathrm{Xu}{ }^{1,3}$, Shengping Yang ${ }^{4}$, Hui Liang ${ }^{1,5}$, Yunxin Zhang ${ }^{6}$, Yali Liu ${ }^{1,7,8}$
}

${ }^{1}$ The Evidence-Based Medicine Center, School of Basic Medical Sciences, Lanzhou University, Lanzhou, China; ${ }^{2}$ Liver Cancer Institute of Zhongshan Hospital, Fudan University, Shanghai, China; ${ }^{3}$ Department of Neurology, Sun Yat-Sen Memorial Hospital, Sun Yat-sen University, Guangzhou, China; ${ }^{4}$ Quanzhou Orthopedic-traumatologigal Hospital, Quanzhou 362000, China; ${ }^{5}$ The First Clinical Medicine College of Lanzhou University, Lanzhou, China; ${ }^{6}$ Department of Urology, Institute of Urology, The Second Hospital of Lanzhou University, Lanzhou, China; ${ }^{7}$ Institute of Basic Research in Clinical Medicine, China Academy of Chinese Medical Sciences, Beijing, China $;^{8}$ Key Laboratory of Clinical Translational Research and EvidenceBased Medicine of Gansu Province, Lanzhou, China

\section{ABSTRACT}

Purpose: To evaluate the efficacy and safety of onabotulinumtoxinA for patients with neurogenic detrusor overactivity (NDO).

Materials and Methods: We searched the Cochrane Library, PUBMED, EMBASE, Chinese Bio-medicine database, China Journal Full-text Database, VIP database, Wanfang database for randomized controlled trials (from inception to September 2012). Two authors independently selected studies, extracted data and assessed the methodological and evidence quality using the Cochrane Risk of Bias Table and GRADE (Grading of Recommendations, Assessment, Development and Evaluation) respectively. Data analysis was performed by RevMan 5.1 and descriptive analysis was employed if necessary. Results: Eight studies were selected ( $\mathrm{n}=1879$ participants). OnabotulinumtoxinA was more related to urinary tract infection (UTI) (200U: OR 1.72, CI: 1.18-2.52; 300U: OR 1.88, CI: 1.31-2.69) versus placebo. Also, OnabotulinumtoxinA was superior to placebo in improving maximum cystometric capacity (MCC) (200U: OR 138.80, CI: 112.45165.15; 300U: OR 152.09, CI: 125.25-178.93) and decreasing maximum detrusor pressure (MDP) (200U: MD -29.61, CI: -36.52--22.69; 300U: MD-28.92, CI: -39.59--18.25). However, there were no statistical differences between $200 \mathrm{U}$ and $300 \mathrm{U}$ onabotulinumtoxinA in UTI (OR 0.84, CI: 0.58-1.22), MCC (OR-12.72, CI: -43.36-17.92) and MDP (MD 2.21, CI: -6.80-11.22).

Conclusions: OnabotulinumtoxinA may provide superior clinical and urodynamic benefit for populations with NDO. High-quality studies are required for evaluating the optimal dose, long-term application and when to perform repeated injections.

\section{ARTICLE INFO}

Key words:

onabotulinumtoxinA

[Supplementary Concept];

Randomized Controlled Trials as

Topic; Meta-Analysis [Publication

Type]; Review Literature as Topic

Int Braz J Urol. 2015; 41: 207-19

Submitted for publication:

March 19, 2014

Accepted after revision:

June 08, 2014

\section{INTRODUCTION}

Overactive bladder syndrome $(\mathrm{OAB})$ is described as the urgency-frequency syndrome, with or without urgent urinary incontinence (1). One type is neurogenic detrusor overactivity (NDO), secondary to spinal cord injury and multiple sclerosis (2). Subjects with NDO are characterized by involuntary bladder contractions at low volumes, low bladder capacity and incontinence, and often 
have high transient bladder pressures. NDO negatively affects the quality of life (QoL) and causes complications within this population like depression, poor sleep, urinary tract infections, skin infections and disturbances of sexual lives (3).

Current treatment options mainly consist of medications (antimuscarinic drugs), behavior adjustments (timing training, bladder retraining, pelvic floor training), surgeries and interventional therapies. Although symptoms can be improved, unsatisfactory effects still exist in many cases. For example, antimuscarinics, the first-line medication (4), can have troublesome side effects, such as dry mouth, constipation as well as blurred vision (5).

FDA approved onabotulinumtoxinA for the treatment of NDO in August 2011. OnabotulinumtoxinA has exerted a positive impact on the urodynamic parameters, urinary continence and QoL $(6,7)$ by preventing the release of acetylcholine at the neuromuscular junction in the afferent and efferent (8) pathways of the bladder wall, urothelium or lamina propria, to inhibit detrusor contraction. Positioned between oral anticholinergic treatment that was ineffective or not tolerated and invasive surgery, this therapy is a minimally invasive treatment option (9). Economically, onabotulinumtoxinA causes a significant reduction in the morbidity as well as in the costs associated with necessary medications (10).

Currently, to our knowledge, there is no consensus regarding the clinical effect of onabotulinumtoxinA on the NDO and different doses, though plenty of relevant articles have been published. Additionally, no articles have been subjected to grade the quality of the overall evidence. Systematic review is of great importance to summarize evidence accurately and reliably. We aim to provide more insight into these topics based on recent randomized controlled trials.

\section{MATERIALS AND METHODS} cluded.

Only randomized controlled trials were in-

\section{Types of participants}

Participants diagnosed with NDO that are defined by the International Continence Society
(ICS) (1) regardless of race, age, gender, course of disease and the origin of studies were included.

\section{Types of interventions}

OnabotulinumtoxinA was in the treatment group. The control group included any other interventions.

\section{Types of outcome measures}

Primary outcomes: Quality of life [scores of the QOL by means of the Incontinence QOL questionnaire, I-QOL (11); King's Health Questionnaire, KHQ (12)]. The most frequent adverse events: urinary tract infection (13).

Secondary outcomes: The frequency of urinary incontinence episodes; Two key urodynamic parameters: MCC (maximum cystometric capacity) and MDP (maximum detrusor pressure).

\section{Search methods for identifiation of studies}

A comprehensive search was performed of the Cochrane Library (2012, 9 issue), PUBMED (1966 to September 2012), EMBASE (1974 to September 2012), Chinese Bio-medicine database (1978 to September 2012), China Journal Full-text Database (1979 to September 2012), VIP database (1989 to September 2012), Wanfang database without language restrictions.

The main keywords were: urinary bladder diseases, bladder overactivity, detrusor overactivity, onabotulinumtoxina, clostridium botulinum toxins. Part of the databases applied subject headings. Search strategies were adjusted adhering to characteristics of different databases. The search strategy for PUBMED is presented in supplementary information.

\section{DATA COLLECTION AND ANALYSIS}

\section{Selection of Studies}

Two researchers independently scanned titles and abstracts consistent with predetermined criteria. Next, they read full texts and determined whether they were eligible. Disagreements were mediated and discussed with a third person. Contact with the authors by e-mail was carried out if any information was not available. 


\section{Assessment of risk of bias}

The risks of bias of the included studies were independently assessed by two reviewers correlating with methods recommended by The Cochrane Collaboration. It was judged by the following criteria: sequence generation, allocation concealment, blinding, incomplete outcome data, selective outcome reporting and other sources of bias. These criteria were judged as: 'Yes' (low risk of bias), 'No' (high risk of bias), or 'Unclear' (unclear or unknown risk of bias).

\section{QUALITY ASSESSIMENT OF THE EVIDENCE}

The overall quality of evidence was assessed for every outcome using GRADE (14) by one reviewer and was validated by a second person with the GRADE pro Version 3.6 software. Five study limitations (Limitations in study design or execution (risk of bias), inconsistency of results, indirectness of evidence, imprecision and reporting bias) were assessed. The confidence of our estimated effect size was reflected through high, moderate, low or very low quality.

\section{Statistical analysis}

Statistical analysis was performed using the Review Manager software 5.1. Relative risk (RR) or odd ratio (OR), along with 95\% confidence interval (CI) was calculated for dichotomous data. Mean difference (MD) with 95\% confidence interval (CI) was calculated for continuous data. Heterogeneity between different studies was assessed by $\chi^{2}$ test with $\mathrm{p}<0.10$ used to indicate statistical significance and measure the quantity of heterogeneity, with $\mathrm{I}^{2}>50 \%$ indicating significant heterogeneity. The meta-analysis was conducted using the fixed-effect model if there was no statistically significant heterogeneity ( $\mathrm{p} \geq 0.10$, $\mathrm{I} 2 \leq 50 \%$ ). Otherwise, we initially analyzed the reasons of heterogeneity and pooled the data with random-effect models. Descriptive analysis was applied if the data could not be extracted for meta-analysis.

\section{RESULTS}

\section{Description of studies}

Our search included eight eligible studies (15-22) (Table-1). The flow of literature was shown in the PRISMA flow chart (Figure-1).
Risk of bias in included studies and quality of evidence.

The methodology for the individual trial and summary of findings for the main comparisons are delineated in Tables 2 and 3, respectively. We sent e-mails to the authors for unclear information, but no responses were received.

\section{Effects of interventions scores for QoL}

Four studies $(16,17,21,22)$ evaluated the impact of onabotulinumtoxinA $200 \mathrm{U}$ and $300 \mathrm{U}$ on QOL showing robust improvements in the mean change from baseline, which was significantly superior to the effect of placebo. Of these, one study (16) recorded I-QOL total scores $(\mathrm{p}<0.05)$ at week 2, 6, 12 and 24. The remaining three studies (17, $21,22)$ recorded it at weeks 6 and $12(\mathrm{p}<0.001)$.

Two studies $(18,19)$ separately compared onabotulinumtoxinA 300U (18) and 500U (19) to placebo according to I-QOL total QOL scores (18) and the Qualiveen questionnaire (19), both showing greater improvement from baseline.

The frequency of urinary incontinence episodes

Compared to placebo, significant reduction of the frequency of urinary incontinence episodes in onabotulinumtoxinA group was seen in seven studies (15, 17-22).

Four studies $(15,17,21,22)$ compared onabotulinumtoxinA $200 \mathrm{U}$ and $300 \mathrm{U}$ groups to placebo. One study (15) revealed the decrease at weeks 12 and 18 in the $200 \mathrm{U}$ onabotulinumtoxinA group. One study (21) reported the reduction at week 6 (-21.8 and-19.4 for the 200 and 300 U groups, respectively, vs. -13.2 for placebo; $\mathrm{P}<0.01)$. Cruz et al. (17) (200U: $p<0.001, p<0.01, p<0.01 ; 300 U$ : $p<0.01$, $\mathrm{p}<0.01, \mathrm{p}<0.001)$ and Ginsberg et al. $(22)(\mathrm{p} \leq 0.008)$ showed the efficacy at weeks 2,6 , and 12 . Furthermore, three studies $(15,17-22)$ found that there were no clinically relevant differences between the onabotulinumtoxinA dose groups.

Two studies $(18,19)$ separately compared onabotulinumtoxinA 300U (18) and 500U (19) to placebo at weeks $6(\mathrm{p}<0.0001), 24(\mathrm{p}=0.0007)$, $36(\mathrm{p}=0.0112)(18)$ and at $0-6$ weeks $(\mathrm{p}<0.001)$, 7-12weeks ( $p=0.002), 13-26$ weeks $(p=0.010)(19)$. OnabotulinumtoxinA was compared with RTX in one study (20) at months 6, 12, $18(\mathrm{p}<0.05)$. 
Table 1 - Characteristics of included studies.

\begin{tabular}{|c|c|c|c|c|c|c|c|c|}
\hline Study & year & $\mathrm{T} / \mathrm{C}$ & $\begin{array}{l}\text { Gender } \\
(\mathrm{M} / \mathrm{F})\end{array}$ & $\begin{array}{l}\text { No. of } \\
\text { patient } \\
\text { (T/C) }\end{array}$ & $\begin{array}{l}\text { Age, mean } \\
(\mathrm{SD}) \text {, years }\end{array}$ & $\begin{array}{c}\text { Way of } \\
\text { anesthesia }\end{array}$ & $\begin{array}{l}\text { Diseases that } \\
\text { causes NDO }\end{array}$ & $\begin{array}{l}\text { The duration of } \\
\text { Follow up }\end{array}$ \\
\hline Schurch et al. (15) & 2005 & $\begin{array}{c}300 U \\
200 U \\
\text { placebo }\end{array}$ & $36 / 23$ & $\begin{array}{l}19 \\
19 \\
21\end{array}$ & $41(20-72)$ & $\begin{array}{c}\text { general, spinal, } \\
\text { local or no } \\
\text { anesthesia }\end{array}$ & $\begin{array}{l}\text { spinal cord injury } \\
\text { and multiple } \\
\text { sclerosis }\end{array}$ & $\begin{array}{c}2,6,12,18 \text { and } \\
24 \text { weeks }\end{array}$ \\
\hline Schurch et al. (16) & 2007 & $\begin{array}{c}300 \mathrm{U} \\
200 \mathrm{U} \\
\text { placebo }\end{array}$ & 59 & - & $21-73$ & - & - & $\begin{array}{c}2,6,12,18 \text { and } \\
24 \text { weeks }\end{array}$ \\
\hline Cruz et al. (17) & 2011 & $\begin{array}{c}300 U \\
200 U \\
\text { placebo }\end{array}$ & $\begin{array}{l}39 / 52 \\
38 / 54 \\
43 / 49\end{array}$ & $\begin{array}{l}91 \\
92 \\
92\end{array}$ & $\begin{array}{l}44.4 \pm 13.9 \\
46.0 \pm 13.1 \\
46.9 \pm 13.4\end{array}$ & $\begin{array}{c}\text { general, local or } \\
\text { no anesthesia }\end{array}$ & $\begin{array}{l}\text { spinal cord injury } \\
\text { and multiple } \\
\text { sclerosis }\end{array}$ & $\begin{array}{c}2,6,12 \text { and } 52 \\
\text { weeks }\end{array}$ \\
\hline $\begin{array}{l}\text { Herschorn et al. } \\
\text { (18) }\end{array}$ & 2011 & $\begin{array}{l}300 \mathrm{U} \\
\text { placebo }\end{array}$ & $\begin{array}{l}15 / 13 \\
19 / 10\end{array}$ & $\begin{array}{l}28 \\
29\end{array}$ & $\begin{array}{l}42.0 \pm 13.3 \\
43.7 \pm 14.3\end{array}$ & $\begin{array}{l}\text { general or local } \\
\text { anesthesia }\end{array}$ & $\begin{array}{l}\text { spinal cord injury } \\
\text { and multiple } \\
\text { sclerosis }\end{array}$ & $\begin{array}{c}1,34,6,24 \text { and } \\
36 \text { weeks }\end{array}$ \\
\hline Ehren et al. (19) & 2007 & $\begin{array}{c}500 U \\
\text { placebo }\end{array}$ & $17 / 14$ & $\begin{array}{l}17 \\
14\end{array}$ & $36(21-66)$ & $\begin{array}{l}\text { general or local } \\
\text { anesthesia }\end{array}$ & $\begin{array}{c}\text { spinal cord injury, } \\
\text { multiple sclerosis, } \\
\text { myelomeningocele, } \\
\text { trauma at birth and } \\
\text { myelitis }\end{array}$ & 26 weeks \\
\hline $\begin{array}{l}\text { Giannantoni et } \\
\text { al. (20) }\end{array}$ & 2004 & $\begin{array}{l}300 \mathrm{U} \\
\mathrm{RTX}\end{array}$ & $18 / 7$ & $\begin{array}{l}12 \\
13\end{array}$ & $38.4 \pm 12.5$ & $\begin{array}{c}\text { spinal } \\
\text { anesthesia and } \\
\text { sedation }\end{array}$ & $\begin{array}{l}\text { chronic spinal cord } \\
\text { injury }\end{array}$ & $\begin{array}{c}14.2 \pm 3.9 \text { months } \\
14.8 \pm 3 \text { months }\end{array}$ \\
\hline $\begin{array}{l}\text { Sussman et } \\
\text { al.(21) }\end{array}$ & 2012 & $\begin{array}{c}300 U \\
200 U \\
\text { placebo }\end{array}$ & $\begin{array}{l}39 / 52 \\
39 / 53 \\
43 / 49\end{array}$ & $\begin{array}{l}91 \\
92 \\
92\end{array}$ & $\begin{array}{l}44.4(13.9) \\
46.0(13.1) \\
46.9(13.4)\end{array}$ & - & $\begin{array}{l}\text { multiple sclerosis } \\
\text { and spinal cord } \\
\text { injury }\end{array}$ & 6 and 12 weeks \\
\hline $\begin{array}{l}\text { Ginsberg et al. } \\
\text { (22) }\end{array}$ & 2012 & $\begin{array}{c}300 U \\
200 U \\
\text { placebo }\end{array}$ & $\begin{array}{l}43 / 89 \\
55 / 80 \\
73 / 76\end{array}$ & $\begin{array}{l}132 \\
135 \\
149\end{array}$ & $\begin{array}{l}47 \pm 12 \\
46 \pm 14 \\
46 \pm 13\end{array}$ & $\begin{array}{l}\text { no anesthesia, } \\
\text { local anesthetic } \\
\text { instillation } \\
\text { without or } \\
\text { with sedation, } \\
\text { or general } \\
\text { anesthesia }\end{array}$ & $\begin{array}{l}\text { multiple sclerosis } \\
\text { and spinal cord } \\
\text { injury }\end{array}$ & $\begin{array}{c}2,6 \text { and } 12 \\
\text { weeks }\end{array}$ \\
\hline
\end{tabular}

$\mathbf{T}=$ The treatment group; $\mathbf{C}=$ The control group .

\section{Adverse events}

All studies reported adverse events. Of these, four studies $(15,17,18,22)$ reported the rate of UTI. There was no statistical heterogeneity between subgroup studies (200U: $p=0.59, \mathrm{I} 2=0 \%$; 300U: $p=0.72, I 2=0 \% ; 200 U$ versus $300 U: p=0.35$, $\mathrm{I} 2=5 \%$ ), and the pooled data showed that the rate in onabotulinumtoxinA 200U (OR 1.72, CI: 1. 18-
2.52) $(15,17,22)$ and 300U(OR 1.88, CI: 1.31-2.69) $(15,17,18,22)$ (Figure-2) group was both significantly higher than that in placebo. Also, there was no statistical heterogeneity between the two treatment groups (OR 0.84, CI: 0.58-1.22) $(15,17,22)$. MCC and MDP

Six studies were identified and all reported the outcomes at week 6 . Therefore, we po- 
Figure 1 - The flowchart of literature screening.

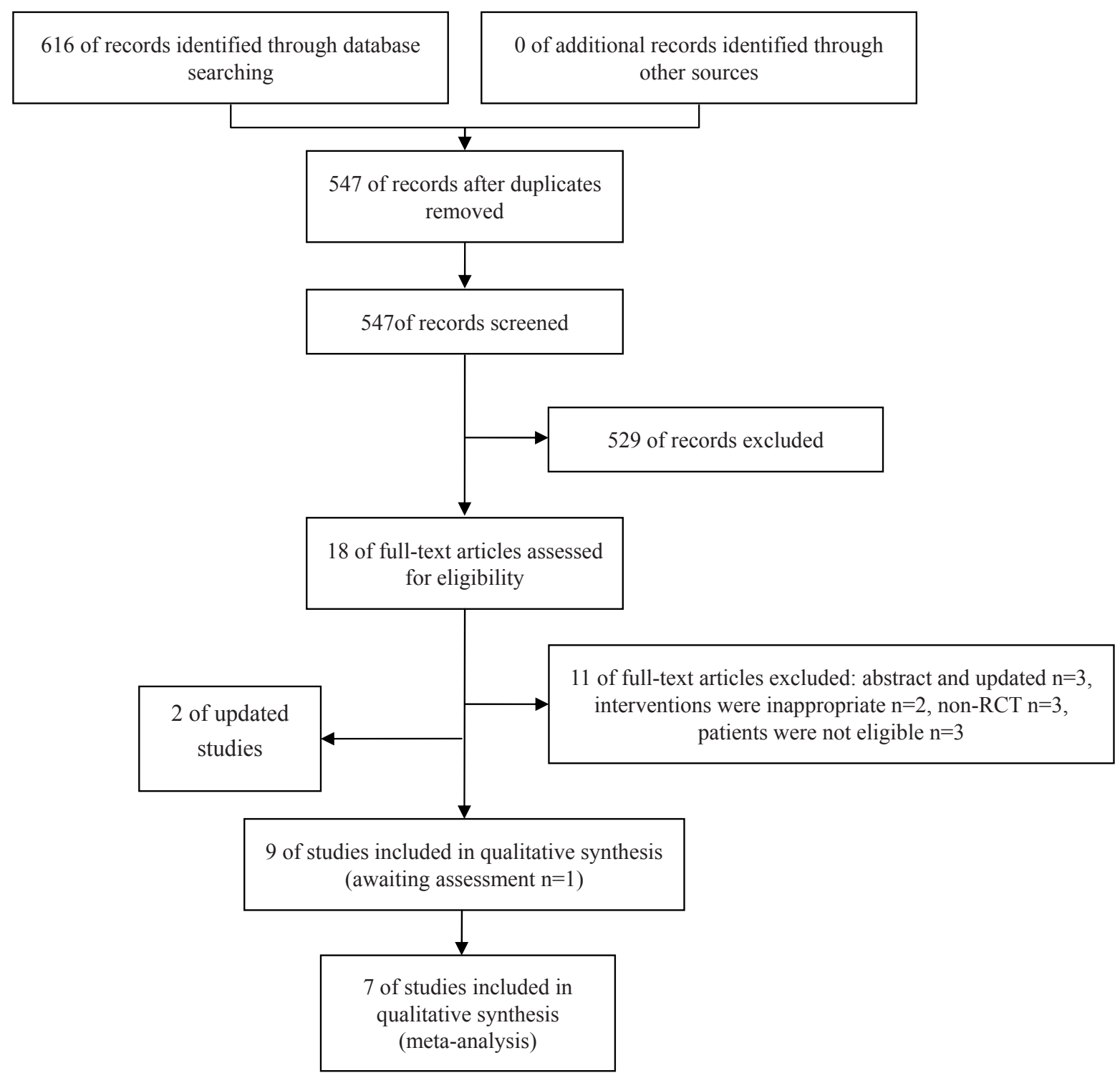

oled the data of week 6 for MCC and MDP, and described the data for other weeks.

Week 6: For MCC, there was no statistical heterogeneity between subgroup studies (200U: $\mathrm{p}=0.81, \mathrm{I}^{2}=0 \% ; 300 \mathrm{U}: \mathrm{p}=0.95, \mathrm{I}^{2}=0 \% ; 200 \mathrm{U}$ versus 300U: $\mathrm{p}=0.81, \mathrm{I}^{2}=0 \%$ ). The result showed that MCC in $200 \mathrm{U}(15,17,22)$ and $300 \mathrm{U}$ onabotulinumtoxinA $(15,17,22)$ groups was both significantly bigger than that in placebo (200U: OR 138.80, CI: 112.45-165.15; 300U: OR 152.09,
CI: 125.25-178.93) (Figure-3). For MDP, there was statistically significant heterogeneity between trials (300U: $\left.p=0.09, I^{2}=59 \%\right)(15,17,22)$. Considering that there was statistical heterogeneity but no significantly clinical heterogeneity among studies, we pooled data with random-effect mode. The result showed that MDP in $200 \mathrm{U}(15,17,22)$ and $300 \mathrm{U}$ onabotulinumtoxinA $(15,17,22)$ group was significantly smaller than that in the placebo group (200U: MD-29.61, CI: -36.52- -22.69; 
300U: MD-28.92, CI: -39.59- -18.25) (Figure-4). Additionally, there were both no statistical differences between 200U and 300U onabotulinumtoxinA in MCC (OR-12.72, CI: -43.36-17.92) (Figure-3) and MDP (MD 2.21, CI: -6.80-11.22) (Figure-4).

Other weeks: One study (15) revealed significant increases and decreases from baseline in MCC $(p \leq 0.020)$ and MDP $(p \leq 0.023)$ in each onabotulinumtoxinA treatment group at all post-treatment time points. One study (18) described the outcome by the use of median showing improvement in urodynamic parameters of onabotulinumtoxinA group (MCC was improved at week 24( $\mathrm{P}=0.031)$; MDP was reduced at week 24 $(\mathrm{P}=0.0006), 36(\mathrm{P}=0.0011)$. Similar findings existed in one study (19) (MCC was improved at 12 weeks $(\mathrm{p}=0.026)$; MDP was reduced $(\mathrm{p}<0.01)$ throughout the whole study period). One study (20) detected an improvement in MCC and MDP $(\mathrm{p}<0.01)$ in onabotulinumtoxinA group compared with RTX at 6,12 and 18-month.

\section{DISCUSSION}

This research was designed in order to evaluate onabotulinumtoxinA for patients with NDO. Five outcomes were monitored: quality of life, urinary incontinence episodes, adverse events, MCC and MDP. Totaling three outcomes (UTI, MCC, MDP) were applied GRADE to assess the quality of evidence. Regrettably, no high quality of evidence was found to favor the effect of onabotulinumtoxinA on them illustrating that the confidence for our conclusion was not very strong. We solely analyzed two key urodynamic parameters (MCC and MDP) due to the paucity of other well-reported parameters in most studies. Similarly, we only performed a meta-analysis for UTI, but not for other adverse events, such as dysreflexia or muscular weakness. Six studies commented on the duration of clinical effect $(15-19,22)$. The duration was maintained for 24 weeks $(15,16), 42.1$ weeks (17), 26 weeks (19), and 254-256 days (22). And improvements were evident at week 6 and persisted to weeks 24 to 36 (18). The clinical effect of the therapy was transient and dose related, whereas solely three studies $(17,20,22)$ mentioned repeated injection. Intervals between reinjections were 6.8 \pm 1.5 months (20) and 295-337 days (22). Moreover, repeat efficacies (reduced weekly UI episodes and maximum detrusor pressure, increased MCC and I-QOL total summary score) were observed $(17,20)$. Considering the inconsistent results reporting, our review was not designed specifically to assess duration of the clinical effect, reinjection effect, interval between reinjections, or other symptoms as urgency. The antimuscarinic co-treatment

Table 2 - Risk of bias in included studies.

\begin{tabular}{|c|c|c|c|c|c|c|}
\hline Study & $\begin{array}{c}\text { Sequence } \\
\text { generation }\end{array}$ & $\begin{array}{c}\text { Allocation } \\
\text { concealment }\end{array}$ & Blinding & $\begin{array}{c}\text { Incomplete } \\
\text { outcome data }\end{array}$ & $\begin{array}{l}\text { Selective } \\
\text { outcome } \\
\text { reporting }\end{array}$ & $\begin{array}{c}\text { Other sources } \\
\text { of bias }\end{array}$ \\
\hline Schurch et al. (15) & Yes* $^{*}$ & Unclear & Yes $\|$ & Yes & Unclear & Unclear \\
\hline Schurch et al. (16) & Unclear & Unclear & Yes $\|$ & Unclear & Unclear & Unclear \\
\hline Cruz et al. (17) & Yest & Unclear & Yes $\|$ & Yes & Unclear & Unclear \\
\hline Herschorn et al. (18) & Yesł & Unclear & Yes $\|$ & Yes & Unclear & Unclear \\
\hline Ehren et al. (19) & Unclear & Unclear & Yes $\|$ & Yes & Unclear & Unclear \\
\hline Giannantoni et al. (20) & Yes§ & Unclear & Unclear & Yes & Unclear & Unclear \\
\hline Sussman et al.(21) & Yest & Unclear & Yes $\|$ & Yes & Unclear & Unclear \\
\hline Ginsberg et al. (22) & Unclear & Unclear & Yes $\|$ & Yes & Unclear & Unclear \\
\hline
\end{tabular}

${ }^{*}$ = unique randomization number; $\dagger=$ an automated interactive voice or web response system; $\ddagger=$ sequential treatment assignment numbers; $\S=$ commercially available software; $\|$ = 'double-blind', but the objective of blinding wasn't mentioned 
Table 3 - Summary of findings for the main comparisons

OnabotulinumtoxinA versus Placebo for NDO

Patient or population: patients with NDO

Settings:

Intervention: OnabotulinumtoxinA versus Placebo

\begin{tabular}{|c|c|c|c|c|c|c|}
\hline \multirow[t]{2}{*}{ Outcomes } & \multicolumn{2}{|c|}{ Illustrative comparative risks* $(95 \% \mathrm{CI})$} & \multirow{2}{*}{$\begin{array}{c}\text { Relative } \\
\text { effect }(95 \% \\
\text { CI) }\end{array}$} & \multirow{2}{*}{$\begin{array}{c}\text { No of } \\
\text { Participants } \\
\text { (studies) }\end{array}$} & \multirow{2}{*}{$\begin{array}{c}\text { Quality of } \\
\text { the evidence } \\
\text { (GRADE) }\end{array}$} & \multirow[t]{2}{*}{ Comments } \\
\hline & Assumed risk & Corresponding risk & & & & \\
\hline \multirow{5}{*}{$\begin{array}{l}\text { The rate of UTI } \\
\text { - } 200 \mathrm{~B} \text { BOTOX } \\
\text { versus Control }\end{array}$} & Control & $\begin{array}{l}\text { OnabotulinumtoxinA } \\
\text { versus Placebo }\end{array}$ & \multirow{5}{*}{$\begin{array}{l}\text { OR } 1.72 \\
(1.18 \text { to } \\
2.52)\end{array}$} & \multirow{5}{*}{$\begin{array}{c}501 \\
\text { (3 studies) }\end{array}$} & \multirow{5}{*}{$\begin{array}{c}\oplus \oplus \oplus \ominus \\
\text { moderate }^{1}\end{array}$} & \\
\hline & \multicolumn{2}{|c|}{ Study population } & & & & \\
\hline & 281 per 1000 & $\begin{array}{c}\mathbf{4 0 2} \text { per } \mathbf{1 0 0 0} \\
(316 \text { to } 496)\end{array}$ & & & & \\
\hline & \multicolumn{2}{|c|}{ Moderate } & & & & \\
\hline & 222 per 1000 & $\begin{array}{c}329 \text { per } 1000 \\
(252 \text { to } 418)\end{array}$ & & & & \\
\hline \multirow{4}{*}{$\begin{array}{l}\text { The rate of UTI } \\
\text { - } 300 \mathrm{U} \text { BOTOX } \\
\text { versus Control }\end{array}$} & \multicolumn{2}{|c|}{ Study population } & \multirow{4}{*}{$\begin{array}{l}\text { OR } 1.88 \\
(1.31 \text { to } \\
2.69)\end{array}$} & \multirow{4}{*}{$\begin{array}{c}548 \\
\text { (4 studies) }\end{array}$} & \multirow{4}{*}{$\begin{array}{c}\oplus \oplus \oplus \ominus \\
\text { moderate }^{1}\end{array}$} & \\
\hline & 309 per 1000 & $\begin{array}{c}\mathbf{4 5 6} \text { per } \mathbf{1 0 0 0} \\
(369 \text { to } 546)\end{array}$ & & & & \\
\hline & & rate & & & & \\
\hline & 280 per 1000 & $\begin{array}{c}422 \text { per } 1000 \\
(338 \text { to } 511)\end{array}$ & & & & \\
\hline \multirow{4}{*}{$\begin{array}{l}\text { The rate of UTI } \\
\text { - } 200 \mathrm{U} \text { BOTOX } \\
\text { versus } 300 \mathrm{U} \\
\text { BОTOX }\end{array}$} & \multicolumn{2}{|c|}{ Study population } & \multirow{4}{*}{$\begin{array}{c}\text { OR } \mathbf{0 . 8 4} \\
(0.58 \text { to } \\
1.22)\end{array}$} & \multirow{4}{*}{$\begin{array}{c}480 \\
\text { (3 studies) }\end{array}$} & \multirow{4}{*}{$\begin{array}{c}\oplus \oplus \oplus \ominus \\
\text { moderate }^{1}\end{array}$} & \\
\hline & 434 per 1000 & $\begin{array}{c}392 \text { per } 1000 \\
(308 \text { to } 483)\end{array}$ & & & & \\
\hline & \multicolumn{2}{|c|}{ Moderate } & & & & \\
\hline & 382 per 1000 & $\begin{array}{c}342 \text { per } 1000 \\
(264 \text { to } 430)\end{array}$ & & & & \\
\hline $\begin{array}{l}\text { MCC - } 200 U \\
\text { BOTOX versus } \\
\text { Control ( the } \\
\text { 6th week) }\end{array}$ & & $\begin{array}{l}\text { The mean mcc } \\
\text { - 200u botox } \\
\text { versus control (the } \\
\text { 6th week) in the } \\
\text { intervention groups } \\
\text { was } 138.8 \text { higher } \\
\text { (112.45 to } 165.15 \\
\text { higher) }\end{array}$ & & $\begin{array}{c}508 \\
\text { (3 studies) }\end{array}$ & $\begin{array}{c}\oplus \oplus \oplus \ominus \\
\text { moderate }^{1}\end{array}$ & \\
\hline $\begin{array}{l}\text { MCC - 300U } \\
\text { BOTOX versus } \\
\text { Control (the 6th } \\
\text { week) }\end{array}$ & & $\begin{array}{l}\text { The mean mcc } \\
\text { - } 300 \text { u botox } \\
\text { versus control (the } \\
\text { 6th week) in the } \\
\text { intervention groups } \\
\text { was } 152.09 \text { higher } \\
\text { (125.25 to } 178.93 \\
\text { higher) }\end{array}$ & & $\begin{array}{c}504 \\
\text { (3 studies) }\end{array}$ & $\begin{array}{c}\oplus \oplus \oplus \ominus \\
\text { moderate }^{1}\end{array}$ & \\
\hline
\end{tabular}




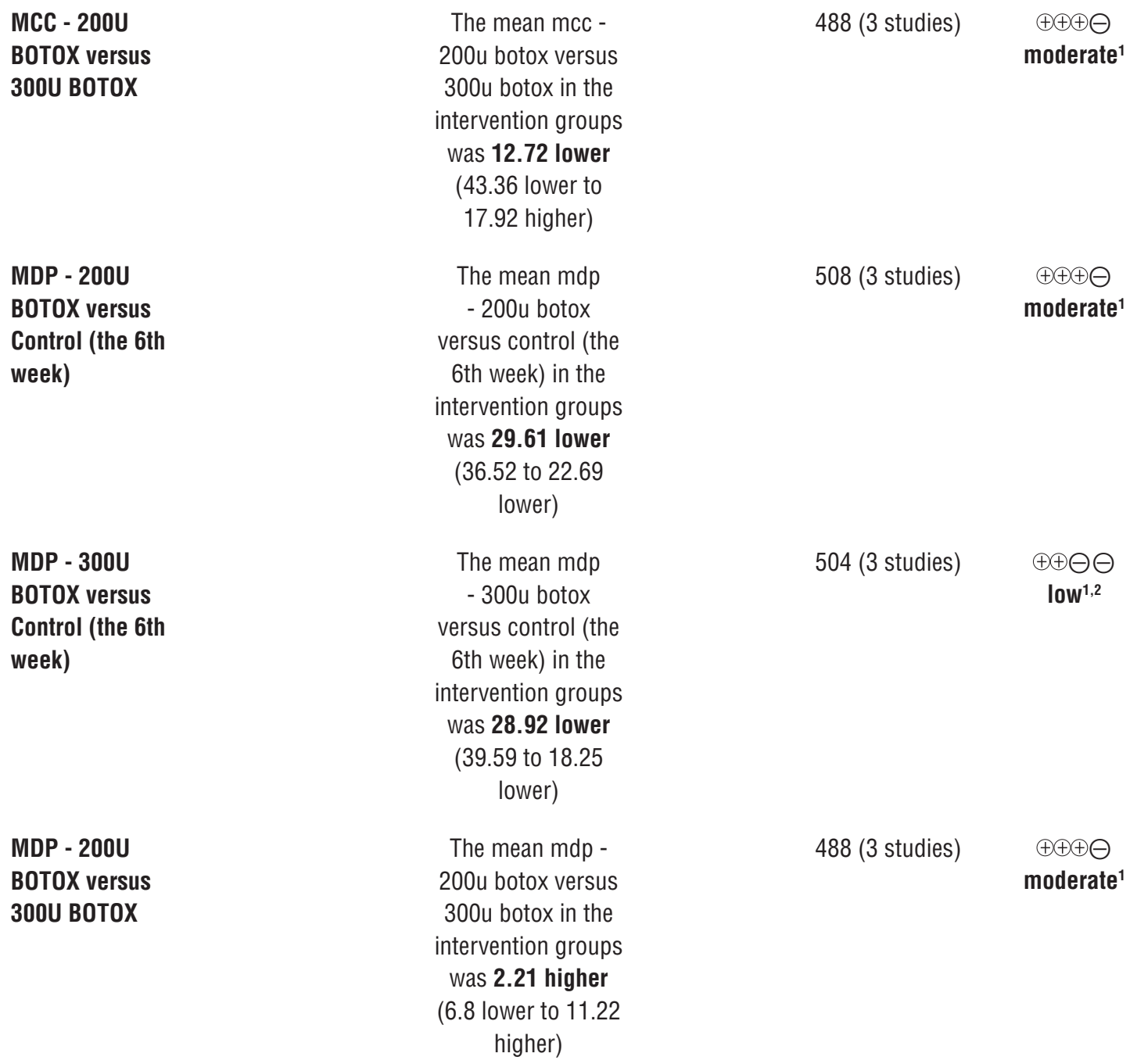

*The basis for the assumed risk (e.g. the median control group risk across studies) is provided in footnotes. The corresponding risk (and its $95 \%$ confidence interval) is based on the assumed risk in the comparison group and the relative effect of the intervention (and its 95\% CI). Cl: Confidence interval; OR: Odds ratio.

\section{GRADE Working Group grades of evidence}

High quality $=$ Further research is very unlikely to change our confidence in the estimate of effect.

Moderate quality $=$ Further research is likely to have an important impact on our confidence in the estimate of effect and may change the estimate. Low quality = Further research is very likely to have an important impact on our confidence in the estimate of effect and is likely to change the estimate.

Very low quality $=$ We are very uncertain about the estimate.

${ }^{1}$ From the result of risk of bias, sequence generation, allocation concealment and blinding of some studies were assessed as "unclear".

${ }^{2}{ }^{2}>50 \%$. 
Figure 2 - Forest plot for the outcome of the rate of urinary tract infection (UTI).

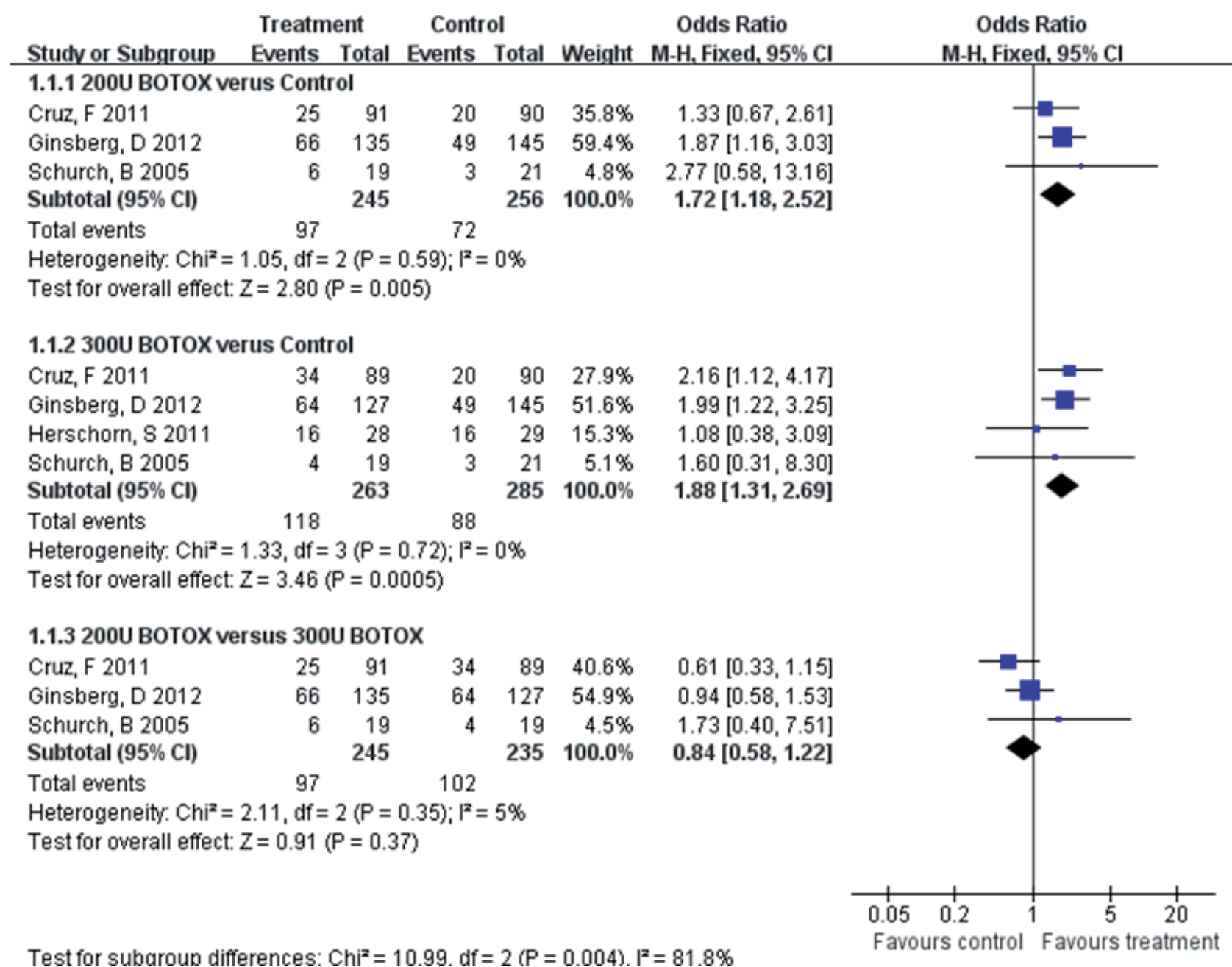

was a major bias on results, and was performed in seven studies $(15,17,18-22)$. However, only three studies (18-20) revealed that patients treated with onabotulinumtoxinA could use a smaller amount of antimuscarinics; therefore, its potential impact on the efficacy of Botox cannot be definitely appraised. Meanwhile, effective and well tolerated monotherapy effect of BoNTA in patients with NDO has also been reported by Grise et al. (23).

There were clinical studies and systematic reviews $(23,24)$ concerning onabotulinumtoxinA for ND0. The Cochrane Review (24) was published on the same subject as our review but with some differences in design, such as types of stu- dies and participants. Additionally, their conclusions have some other points that contrast with ours: 1. The Cochrane Review revealed that lower doses of botulinum toxin (100 to $150 \mathrm{U}$ ) appeared to have beneficial effects, but larger doses (300 U) may have been more effective and longer lasting, but with more side effects. However, our review did not find clear dose differences (200 VS $300 \mathrm{U}) ; 2$. The Cochrane Review revealed that suburothelial injection had comparable efficacy to intradetrusor injection. However, our review did not compare different site injections because all included studies that applied intradetrusor injection. 3. The Cochrane Review indicated that the 
Figure 3 - Forest plot for the outcome of maximum cystometric capacity (MCC).

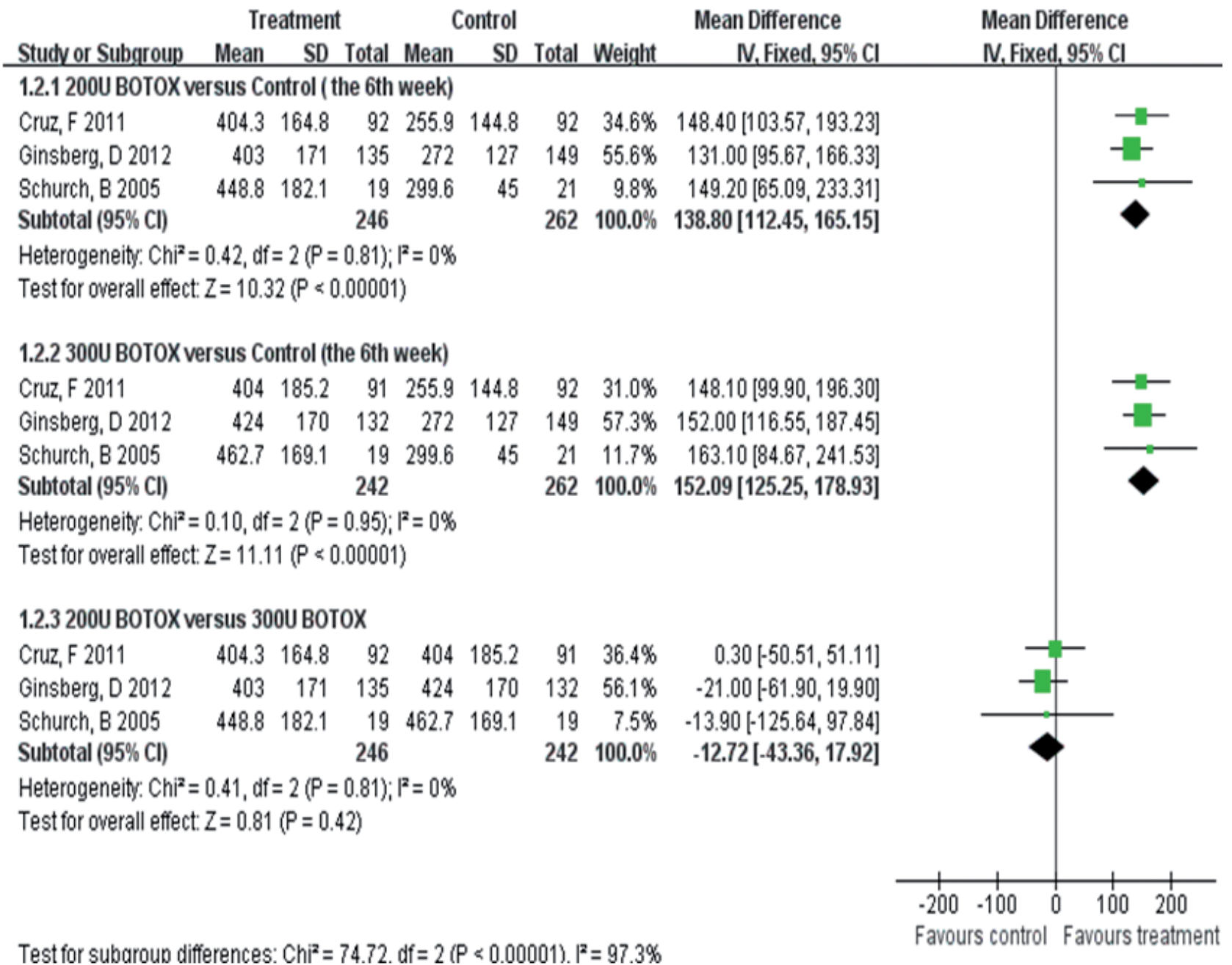

effect of botulinum toxin may last for a number of months and is dependent upon dose and type of toxin used. However, our review was not designed specifically to assess duration of the clinical effect duo to inconsistent report of results. Moreover, our research was mainly about onabotulinumtoxinA for NDO due to the dearth of studies about onabotulinumtoxinB. Regrettably, in spite of some similar conclusions, long term outcomes, safety, and optimal dose of botulinum toxin for $\mathrm{OAB}$ all remain still unanswered. To our acknowledge, our systematic review is the first to highlight a dose difference in terms of clinical effect and grade the quality of evidence in accordance with GRADE to reflect the confidence of our estimated effect size.
However, it is still unknown whether higher or lower doses are more beneficial for patients due to the failure of finding clear difference between 200U and 300U. More studies should be initiated to determine the optimal dosage.

Methodological deficiency makes it difficult to reach more valid and reliable decisions. Six trials reported adequate randomization and one trial performed the exact allocation concealment. However, the remaining failed to mention the information above, which indicates the existence of selection bias. Seven trials performed blinding choice and most were double-blinded. Mostly, we considered objectives as patients and doctors. For subjective measurement, the score of QoL, was susceptible to 
Figure 4 - Forest plot for the outcome of maximum detrusor pressure (MDP).

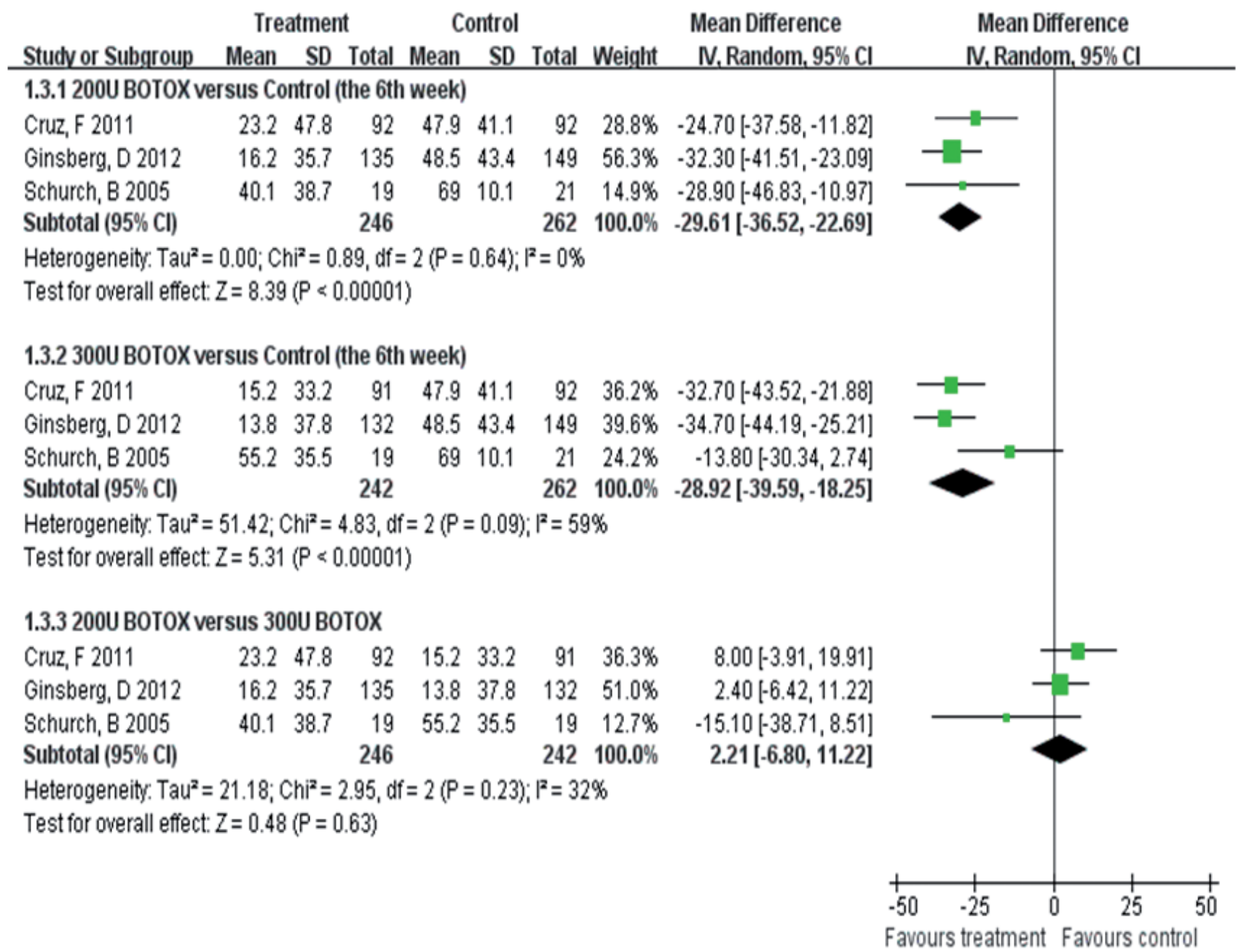

performance bias and detection bias. One trial failed to implement the blinding implying the possibility of performance bias.

During treatment, some failed to perform anesthesia before injection, while others required general, local and spinal anesthesia (Table-1). We should also pay close attention to those patients who have a failure or intolerance to onabotulinumtoxinA to ensure its safety. The possible plausible explanation for this may be the emergence of an antibody or variation of axolemma receptor's structures and tissues (25).

Some limitations for our systematic review should be acknowledged. First, published results were hindered by small sample size, and vague des- cription about the allocation concealment in findings. Second, it is sufficient to raise doubts about long-term application owing to the short-term studies, with only one with duration up to 18 months. Third, our research was mainly about onabotulinumtoxinA for NDO due to the dearth of studies about onabotulinumtoxinB. We hope high quality of RCTs in this field will be implemented in the future. Forth, one concern we have is that the conclusion of having more UTI after onobotulinumtoxin cannot be accurately answered without a uniform definition of a UTI due to the significant difference between laboratory infections and clinical infections. Finally, it is also worth noting that GRADE's approach to assess risk of bias shares some fundamental limi- 
tations with the very large number of alternative approaches. For example, empirical evidence supporting the criteria is limited and attempts to show systematic difference between studies that meet or do not meet specific criteria shows inconsistent results. Furthermore, the relative weight one should put on the criteria remains uncertain.

\section{CONCLUSIONS}

OnabotulinumtoxinA appears to be a cost-effective intervention for populations with NDO; however, the findings are not strongly definitive based on limited trials. In addition, we fail to find any dose differences.

\section{Search Strategy for PUBMED}

\# 1 Botulinum Toxin* OR botuli* OR Botulinu* toxin* OR "Clostridium botulinum Toxins" OR "Clostridium botulinum" OR onobotulinumtoxin

\#2 "Botulinum Toxins"[Mesh]

\#3 \# 1 OR \#2

\#4 "bladder overactivity" OR "detrusor overactivity" OR "overactive urinary bladder" OR "overactive bladder symptoms" OR "detrusor hyperreflexia" OR "urinary urgency" OR "urinary incontinence" OR "Urinary Bladder Diseases" OR "bladder dysfunction"

\#5 “Urinary Bladder Diseases" (Mesh)

\#6 \#4 OR \#5

\#7 "Randomized Controlled Trial" (Publication Type)

\#8 "Randomized Controlled Trials as Topic”(Mesh) \#9 "Controlled Clinical Trial” (Publication Type)

\# 10 "Controlled Clinical Trials as Topic"(Mesh)

\# 11 randomized (Title/Abstract)

\# 12 placebo (Title/Abstract)

\#13 drug therapy (MeSH Subheading)

\# 14 randomly (Title/Abstract)

\# 15 trial (Title/Abstract)

\# 16 groups (Title/Abstract)

\#17 \#7 OR \#8 OR \#9 OR \#10 OR \#11 OR \#12 OR

\#13 OR \#14 OR \#15 OR \#16

\#18 "Animals" (Mesh)

\# 19 "Humans" (Mesh)

\#20 \#18 NOT \#19\#21 \#17 NOT \#20

\#22 \#3 AND \#6 AND \#21

\section{ACKNOWLEDGMENTS}

The authors thank Tracy, Stacie, Bing Bai, Jinqiu Yuan and YuanjunTeng that provided assistance with comments on revising the final manuscript. No financial or research funding are disclosed.

\section{CONFLICT OF INTEREST}

None declared.

\section{REFERENCES}

1. Abrams P, Cardozo L, Fall M, Griffiths D, Rosier P, Ulmsten $U$, et al. Standardisation Sub-committee of the International Continence Society. The standardisation of terminology of lower urinary tract function: report from the Standardisation Sub-committee of the International Continence Society. Neurourol Urodyn. 2002;21:167-78.

2. Duthie J, Wilson DI, Herbison GP, Wilson D. Botulinum toxin injections for adults with overactive bladder syndrome. Cochrane Database Syst Rev. 2007;(3):CD005493. Update in: Cochrane Database Syst Rev.2011;(12):CD005493.

3. Giannantoni A, Mearini E, Del Zingaro M, Porena M. Six-year follow-up of botulinum toxin A intradetrusorial injections in patients with refractory neurogenic detrusor overactivity: clinical and urodynamic results. Eur Urol. 2009;55:705-11.

4. Cameron AP. Pharmacologic therapy for the neurogenic bladder. Urol Clin North Am. 2010;37:495-506.

5. Jundt K, Schreyer K, Friese K, Peschers U. Anticholinergic therapy: do the patients take the pills prescribed? Arch Gynecol Obstet. 2011;284:663-6.

6. Bagi P, Biering-Sørensen F. Botulinum toxin A for treatment of neurogenic detrusor overactivity and incontinence in patients with spinal cord lesions. Scand J Urol Nephrol. 2004;38:495-8.

7. Grosse J, Kramer G, Stöhrer M. Success of repeat detrusor injections of botulinum a toxin in patients with severe neurogenic detrusor overactivity and incontinence. Eur Urol. 2005;47:653-9.

8. Gomes CM, Castro Filho JE, Rejowski RF, Trigo-Rocha FE, Bruschini $\mathrm{H}$, Barros Filho TE, et al. Experience with different botulinum toxins for the treatment of refractory neurogenic detrusor overactivity. Int Braz J Urol. 2010;36:66-74.

9. Schurch B, Stöhrer M, Kramer G, Schmid DM, Gaul G, Hauri D. Botulinum-A toxin for treating detrusor hyperreflexia in spinal cord injured patients: a new alternative to anticholinergic drugs? Preliminary results. J Urol. 2000;164:692-7. 
10. Wefer B, Ehlken B, Bremer J, Burgdörfer H, Domurath B, Hampel $C$, et al. Treatment outcomes and resource use of patients with neurogenic detrusor overactivity receiving botulinum toxin A (BOTOX) therapy in Germany. World $\mathrm{J}$ Urol. 2010;28:385-90.

11. Wagner TH, Patrick DL, Bavendam TG, Martin ML, Buesching DP. Quality of life of persons with urinary incontinence: development of a new measure. Urology. 1996;47:67-71; discussion 71-2.

12. Duckett JR, Hall S. A new questionnaire to assess the quality of life of urinary incontinent women. Br J Obstet Gynaecol. 1998;105:931.

13. Gamé $X$, Castel-Lacanal E, Bentaleb $Y$, Thiry-Escudié I, De Boissezon X, Malavaud B, et al. Botulinum toxin A detrusor injections in patients with neurogenic detrusor overactivity significantly decrease the incidence of symptomatic urinary tract infections. Eur Urol. 2008;53:613-8.

14. Balshem $H$, Helfand $M$, Schünemann $H J$, Oxman $A D$, Kunz $\mathrm{R}$, Brozek J, et al. GRADE guidelines: 3 . Rating the quality of evidence. J Clin Epidemiol. 2011;64:401-6.

15. Schurch $B$, de Sèze $M$, Denys $P$, Chartier-Kastler $E$, Haab F, Everart K, et al. Botox Detrusor Hyperreflexia Study Team. Botulinum toxin type $a$ is a safe and effective treatment for neurogenic urinary incontinence: results of a single treatment, randomized, placebo controlled 6-month study. J Urol. 2005;174:196-200.

16. Schurch B, Denys $P$, Kozma CM, Reese PR, Slaton T, Barron RL. Botulinum toxin A improves the quality of life of patients with neurogenic urinary incontinence. Eur Urol. 2007;52:850-8.

17. Cruz F, Herschorn S, Aliotta P, Brin M, Thompson C, Lam W, et al. Efficacy and safety of onabotulinumtoxinA in patients with urinary incontinence due to neurogenic detrusor overactivity: a randomised, double-blind, placebo-controlled trial. Eur Urol. 2011;60:742-50.

18. Herschorn S, Gajewski J, Ethans K, Corcos J, Carlson K, Bailly $G$, et al. Efficacy of botulinum toxin $A$ injection for neurogenic detrusor overactivity and urinary incontinence: a randomized, double-blind trial. J Urol. 2011;185:2229-35.

19. Ehren I, Volz D, Farrelly E, Berglund L, Brundin L, Hultling $C$, et al. Efficacy and impact of botulinum toxin A on quality of life in patients with neurogenic detrusor overactivity: a randomised, placebo-controlled, double-blind study. Scand J Urol Nephrol. 2007;41:335-40.
20. Giannantoni A, Di Stasi SM, Stephen RL, Bini V, Costantini E, Porena M. Intravesical resiniferatoxin versus botulinum-A toxin injections for neurogenic detrusor overactivity: a prospective randomized study. J Urol. 2004;172:240-3.

21. Sussman D, Patel V, Del Popolo G, Lam W, Globe D, Pommerville $P$. Treatment satisfaction and improvement in health-related quality of life with onabotulinumtoxinA in patients with urinary incontinence due to neurogenic detrusor overactivity. Neurourol Urodyn. 2013;32:242-9.

22. Ginsberg D, Gousse A, Keppenne V, Sievert KD, Thompson C, Lam W, et al. Phase 3 efficacy and tolerability study of onabotulinumtoxinA for urinary incontinence from neurogenic detrusor overactivity. J Urol. 2012;187:2131-9.

23. Grise $P$, Ruffion $A$, Denys $P$, Egon $G$, Chartier Kastler E. Efficacy and tolerability of botulinum toxin type $A$ in patients with neurogenic detrusor overactivity and without concomitant anticholinergic therapy: comparison of two doses. Eur Urol. 2010;58:759-66.

24. Duthie JB, Vincent M, Herbison GP, Wilson DI, Wilson D. Botulinum toxin injections for adults with overactive bladder syndrome. Cochrane Database Syst Rev. 2011;(12):CD005493.

25. Pellizzari R, Rossetto 0 , Schiavo G, Montecucco $\mathrm{C}$. Tetanus and botulinum neurotoxins: mechanism of action and therapeutic uses. Philos Trans R Soc Lond B Biol Sci. 1999;354:259-68.
Correspondence address: Rui Zhang, MD

The Evidence-Based Medicine Center School of Basic Medical Sciences Lanzhou University, Gansu, China No.199, Dong Gang West Road, Chengguan District, Lanzhou, Gansu, China lanzhou 730000, China E-mail: zhangruicherry52@gmail.com 